\title{
Ultrasound-Guided Continuous Femoral Nerve Block with Dexmedetomidine Combined with Low Concentrations of Ropivacaine for Postoperative Analgesia in Elderly Knee Arthroplasty
}

\author{
Xiao-Ying Zhao ${ }^{a}$ Er-Fei Zhang ${ }^{b}$ Xiao-Li Bai ${ }^{a} \quad$ Zi-Jian Cheng ${ }^{a}$ Peng-Yun Jia ${ }^{a} \quad$ Yan-Nan Li ${ }^{c}$ \\ Zheng Guo ${ }^{a}$ Jian-Xin Yang ${ }^{a}$ \\ ${ }^{a}$ Department of Anesthesiology, The Second Hospital of Shanxi Medical University, Taiyuan, China; ${ }^{b}$ Department of \\ Anesthesiology, The Affiliated Hospital of Yan'an University, Yan'an, China; 'Shanxi Medical University, Taiyuan, China
}

\section{Significance of the Study}

- This study suggests that the use of a combination of dexmedetomidine (DEX) with $0.15 \%$ ropivacaine in ultrasound-guided continuous femoral nerve block for postoperative analgesia in elderly patients with total knee arthroplasty provides a better analgesic effect and a better assessment of satisfaction than without DEX performance.

\section{Keywords}

Dexmedetomidine $\cdot$ Ropivacaine $\cdot$ Continuous femoral nerve block · Total knee arthroplasty

\footnotetext{
Abstract

Objectives: This study aims to investigate the clinical effect of dexmedetomidine (DEX) combined with low concentrations of ropivacaine in ultrasound-guided continuous femoral nerve block for postoperative analgesia in elderly patients with total knee arthroplasty (TKA). Materials and Methods: Patients were divided into three groups: group $C$, group D1, and group D2. For postoperative analgesia, patients in group $C$ were given $0.15 \%$ ropivacaine, patients in group D1 were given $0.15 \%$ ropivacaine $+0.02 \mu \mathrm{g} \times \mathrm{kg}^{-1} \times$ $\mathrm{h}^{-1}$ DEX, and patients in group D2 were given $0.15 \%$ ropivacaine $+0.05 \mu \mathrm{g} \times \mathrm{kg}^{-1} \times \mathrm{h}^{-1}$ DEX. The visual analogue scores in the resting state, active state (AVAS), and passive functional exercise state (PVAS), degree of joint bending, and
}

\begin{tabular}{ll}
\hline KARGER & $\begin{array}{l}\text { (c) } 2019 \text { The Author(s) } \\
\text { Published by S. Karger AG, Basel }\end{array}$ \\
E-Mail karger@karger.com & $\begin{array}{l}\text { This is an Open Access article licensed under the Creative Commons } \\
\text { Attribution-NonCommercial-4.0 International License (CC BY-NC) } \\
\text { (http://www.karger.com/Services/OpenAccessLicense), applicable to } \\
\text { the online version of the article only. Usage and distribution for com- } \\
\text { mercial purposes requires written permission. }\end{array}$
\end{tabular}

Ramsay scores were recorded. Results: The Ramsay scores were significantly higher, AVAS scores were significantly lower, PVAS scores were significantly decreased, the degree of joint bending was significantly higher, and the time to the first postoperative ambulation was shorter in groups D1 and D2 than group C. Furthermore, the time to the first postoperative ambulation was shorter in group D2 than in group D1, patients in groups D1 and D2 were more satisfied than patients in group C, and patients in group D2 were more satisfied than patients in group D1. Conclusion: The protocol of $0.05 \mu \mathrm{g} \times \mathrm{kg}^{-1} \times \mathrm{h}^{-1}$ of DEX combined with $0.15 \%$ ropivacaine in ultrasound-guided continuous femoral nerve block for postoperative analgesia in elderly patients with TKA provides a better analgesic effect than without DEX performance.

(c) 2019 The Author(s)

Published by S. Karger AG, Basel

X.-Y.Z. and E.-F.Z. have contributed equally to this research. 


\section{Introduction}

Total knee arthroplasty (TKA) patients usually refuse to undertake early functional exercise after surgery due to pain, reducing the surgical effect to a large extent. It is reported that $15-20 \%$ of patients are dissatisfied with their surgical outcomes due to postoperative pain [1-3]. Limb activity in the perioperative period and excellent postoperative analgesia play an important role in the early rehabilitation of patients undergoing knee arthroplasty $[4,5]$. Multimode pain management has become the standard for postoperative care of total hip and knee arthroplasty, which includes the use of many different types of drugs for each source of pain, preemptive analgesia, postoperative intravenous patient-controlled analgesia (PCA), patient-controlled epidural analgesia, local nerve block, and local infiltration analgesia. The advantages include the reduction in opioid consumption and relatively mild side effects, promoting early activity and faster functional recovery [6]. However, post-TKA continuous femoral nerve block for analgesia has been reported to be better than intravenous PCA and epidural analgesia [7].

At present, postoperative analgesia methods for joint replacement mainly include continuous nerve block and periarticular injection analgesia. However, the latter is a subject of controversy compared to continuous nerve block in the clinic [2], and particularly its long-term analgesic effect and appropriate dosing remain to be explored [8]. Therefore, peripheral nerve block analgesia is an ideal analgesic strategy. Currently, the local anesthetic ropivacaine is commonly used in surgery, while dexmedetomidine (DEX) combined with ropivacaine could enhance the effect of the arrest and prolong its duration of action $[9,10]$. In addition, it could also reduce inflammatory responses in surgery and inflammation caused by inflammatory pain [11], offering reliable analgesia after surgery. Presently, the concentration of ropivacaine is usually set at $0.2 \%$ [12], but a higher local anesthetic concentration will weaken the muscle strength of the lower limbs, causing inconvenience during postoperative exercise [13]; thus, a lower concentration of ropivacaine $(0.1 \%)$ can also be applied in the clinic [14].

Therefore, the aim of the present study was to explore the clinical effect of DEX combined with low concentrations of ropivacaine in ultrasound-guided continuous femoral nerve block for postoperative analgesia in elderly patients with TKA.

\section{Materials and Methods}

From February to October 2015, elderly inpatients who were ready for elective TKA for the first time, 65-79 years old, 150-180 $\mathrm{cm}$ in height, $50-80 \mathrm{~kg}$ in weight, had grade I-III according to the American Society of Anesthesiologists but not lower extremity nerve dysfunction, severe heart disease, brain disease, liver disease, kidney disease, coagulation disorders, long-term use of sedatives, or puncture site infection were selected for the study. These patients were randomly divided into three groups: a control group (group C) and two DEX groups (groups D1 and D2). A randomized sequence for the three groups in a 1:1:1 ratio was generated, in blocks of four, using a computer-generated random number sequence. After patient screening and randomization, intraoperative allocation was conducted by means of a sealed, number-coded envelope. The envelope contained the anesthesia protocol. Patients, the attending anesthetist, postoperative staff, and data collectors were blinded to group allocation.

Patients did not receive preoperative medication and were routinely monitored after admission through ECG, blood pressure, and blood oxygen saturation $\left(\mathrm{SpO}_{2}\right)$, etc., the peripheral venous catheter was open, and routine fluid infusion was performed.

In the lateral decubitus position, subarachnoid block was performed, the gap at $\mathrm{L}_{3-4}$ was punctured, $7.5-10 \mathrm{mg}$ of $0.5 \%$ ropivacaine (AstraZeneca AB, Södertälje, Sweden) were given [15], and the anesthesia block plane was determined at $\mathrm{L}_{1}-\mathrm{T}_{12}$ level at the beginning of the surgery. No additional analgesia or sedatives were given during the surgery. At the end of the surgery, femoral nerve graft continuous block was induced by ultrasound. The catheterization method was as follows: patients were placed in the supine position, limb extended; a portable ultrasound machine (eZono3000, Jena, Germany) was used, and the ultrasound probe (line probe, frequency 6-13 MHz, eZono3000) was placed in the inguinal region. After capturing the femoral nerve images, the trocars (53115632A, 19Ga50mm; PAJUNK GmbH Medizintechnologie, Geisingen, Germany) were placed around the femoral nerve using the out-of-plane technique. The catheter was positioned at an area $5 \mathrm{~cm}$ away from the skin, fixed by sterile excipients, and then connected to the postoperative PCA system (ZZB-300; NanTong Epsips Medical Devices Co., Ltd., NanTong, China). The PCA formulation was as follows: $0.15 \%$ ropivacaine in group $C, 0.15 \%$ ropivacaine $+0.02 \mu \mathrm{g} \times \mathrm{kg}^{-1} \times \mathrm{h}^{-1}$ DEX (Hengrui Pharmaceutical Co. Ltd., Jiangsu, China) in group D1, and $0.15 \%$ ropivacaine +0.05 $\mu \mathrm{g} \times \mathrm{kg}^{-1} \times \mathrm{h}^{-1} \mathrm{DEX}$ in group D2. All were diluted to $300 \mathrm{~mL}$ with normal saline. The background dose was $5 \mathrm{~mL} / \mathrm{h}$, PCA dose was 10 $\mathrm{mL}$, and locking time was $30 \mathrm{~min}$. If the patient needed an additional analgesic, parecoxib sodium (Pfizer Pharmaceutical Co., Ltd., Kalamazoo, MI, USA) was given according to the instructions.

The visual analogue scores in the resting state and the visual analogue scores in the active state (AVAS) (0 point: painless; 10 points: painful) were determined before surgery and 6, 12, 24, and $48 \mathrm{~h}$ after surgery. Passive functional exercise was performed 24 and $48 \mathrm{~h}$ after surgery (knee joint motion ranged within $20-30^{\circ}$, increasing by $5-10^{\circ}$ daily, 2 times/day, and each was not $<2 \mathrm{~h}$ ). The visual analogue scores in the passive functional exercise state (PVAS) were used to assess the analgesic outcome. The Ramsay sedation score 6, 12, 24 and $48 \mathrm{~h}$ after surgery was used to assess patient sedation effects: 1 point: anxious, agitated or restless; 2 points: quiet; 3 points: sleepy, but having agile response to language stimulation; 4 points: sleepy and having agile response to language; 5 points: sleepy and having 
Table 1. Comparison of general data in each group

\begin{tabular}{|c|c|c|c|c|c|c|c|c|c|c|}
\hline Group & $\begin{array}{l}\text { Males/ } \\
\text { females, } n\end{array}$ & $\begin{array}{l}\text { Age, } \\
\text { years }\end{array}$ & $\begin{array}{l}\text { Height, } \\
\mathrm{cm}\end{array}$ & $\begin{array}{l}\text { Weight, } \\
\text { kg }\end{array}$ & $\begin{array}{l}\text { ASA } \\
\text { (case) } \\
\text { I/II/III }\end{array}$ & $\begin{array}{l}\text { Surgical } \\
\text { side, } n \\
\text { left/right }\end{array}$ & $\begin{array}{l}\text { Intraoperative } \\
\text { anesthesia, } \\
\text { min }\end{array}$ & $\begin{array}{l}\text { Operation } \\
\text { time, min }\end{array}$ & $\begin{array}{l}\text { Tourniquet } \\
\text { time, min }\end{array}$ & $\begin{array}{l}\text { Volume } \\
\text { of bleed- } \\
\text { ing, mL }\end{array}$ \\
\hline D1 & $14 / 16$ & $73.2 \pm 7.3$ & $161.7 \pm 6.5$ & $73.6 \pm 4.7$ & $10 / 13 / 7$ & $20 / 10$ & $70.7 \pm 4.6$ & $56.3 \pm 7.2$ & $48.5 \pm 7.8$ & $85 \pm 15$ \\
\hline D2 & $10 / 20$ & $71.5 \pm 6.3$ & $163.3 \pm 7.5$ & $72.9 \pm 5.5$ & $6 / 18 / 6$ & $14 / 16$ & $78.3 \pm 6.6$ & $58.7 \pm 6.5$ & $55.9 \pm 8.9$ & $88 \pm 12$ \\
\hline
\end{tabular}

Table 2. Comparison of analgesia scores

\begin{tabular}{lllllll}
\hline Index & Group & $\begin{array}{l}\text { Before } \\
\text { surgery }\end{array}$ & \multicolumn{4}{l}{ After surgery } \\
\cline { 4 - 7 } & & & $6 \mathrm{~h}$ & $12 \mathrm{~h}$ & $24 \mathrm{~h}$ & $48 \mathrm{~h}$ \\
\hline RVAS & $\mathrm{C}$ & $3.2 \pm 0.7$ & $1.6 \pm 0.5$ & $1.8 \pm 0.6$ & $1.9 \pm 0.6$ & $2.2 \pm 0.8$ \\
& D1 & $3.3 \pm 0.8$ & $1.4 \pm 0.5$ & $1.6 \pm 0.7$ & $1.7 \pm 0.6$ & $1.9 \pm 0.7$ \\
& D2 & $3.3 \pm 0.8$ & $1.4 \pm 0.6$ & $1.5 \pm 0.6$ & $1.6 \pm 0.7$ & $1.8 \pm 0.8$ \\
\hline AVAS & C & $4.1 \pm 1.3$ & $3.7 \pm 0.8$ & $4.2 \pm 1.0$ & $3.9 \pm 1.0$ & $3.8 \pm 1.0$ \\
& D1 & $4.8 \pm 1.4$ & $3.2 \pm 0.9^{\mathrm{a}}$ & $3.7 \pm 0.7^{\mathrm{a}}$ & $3.4 \pm 0.7^{\mathrm{a}}$ & $3.2 \pm 0.6^{\mathrm{a}}$ \\
& D2 & $4.6 \pm 1.4$ & $3.1 \pm 0.8^{\text {aa }}$ & $3.5 \pm 0.6^{\text {aa }}$ & $3.3 \pm 0.7^{\text {aa }}$ & $3.2 \pm 0.5^{\text {aa }}$ \\
\hline PVAS & C & & & & $4.4 \pm 1.0$ & $4.2 \pm 1.3$ \\
& D1 & & & & $3.9 \pm 0.9$ & $3.6 \pm 0.8$ \\
& D2 & & & & $3.7 \pm 0.8^{\mathrm{a}}$ & $3.5 \pm 0.8^{\mathrm{a}}$ \\
\hline
\end{tabular}

RVAS, visual analogue scores in the resting state; AVAS, visual analogue scores in the active state; PVAS, visual analogue scores in the passive functional exercise state. ${ }^{a} p<$ 0.05 , ${ }^{\text {aa }} p<0.01$, vs. group C.

slow response to language or tactile stimulation; 6 points: drowsy, having no response to language stimulation. At 24 and $48 \mathrm{~h}$ after surgery, knee flexion (the femur extension line and tibia angle, and the degree of curvature was $90^{\circ}$ for the recovery of the target value) and the occurrence of nausea and vomiting situation were recorded. Standards for patient satisfaction on analgesia at $48 \mathrm{~h}$ are as follows: 0 point: pretty much not satisfied; 10 points: extremely satisfied. We used a digital simulation scoring system, as done in a previous study, and a slightly modified digital simulation scoring system for assessment of patient satisfaction on analgesia [16].

SPSS 17.0 statistical software was used for analysis. Normally distributed measurement data were presented as means $\pm \mathrm{SD}$, and comparisons between groups were conducted using one-way analysis of variance. If the data were not normally distributed and/or the variance was not homogeneous, the rank-sum test was applied, and these data were compared between two groups using the Kruskal-Wallis $\mathrm{H}$ test. Count data were evaluated using the $\chi^{2}$ test. The difference was statistically significant when $p<0.05$.

\section{Results}

\section{Patient Characteristics}

A total of 137 patients were recruited for the study. There were no significant differences in gender, age, body weight, height, surgical side, ASA classification, intraoperative anesthesia, operation time, tourniquet time, and volume of bleeding between these three groups (Table 1).

\section{Primary Results}

Compared to group C, AVAS scores in groups D1 and D2 significantly decreased ( $p=0.034$ and 0.015 , respectively, at $6 \mathrm{~h} ; p=0.061$ and 0.004 , respectively, at $12 \mathrm{~h}$; $p=0.04$ and 0.017 , respectively, at $24 \mathrm{~h} ; p=0.006$ and 0.003 , respectively, at $48 \mathrm{~h}$ ) postoperatively. PVAS scores significantly decreased only in group D2 at $24 \mathrm{~h}(p=$ $0.024)$ and 48 h postoperatively $(p=0.048)$ compared to group C (Table 2).

\section{Secondary Results}

The Ramsay scores in groups D1 and D2 were significantly higher than in group $\mathrm{C}(p=0.006$ and 0.003 , respectively, at $6 \mathrm{~h} ; p=0.004$ and 0.001 , respectively, at $12 \mathrm{~h} ; p=0.003$ and 0.001 , respectively, at $24 \mathrm{~h} ; p=0.002$ and 0.001 , respectively, at $48 \mathrm{~h}$ ) postoperatively. The range of joint motion in groups D1 and D2 significantly 
Table 3. Comparison of postoperative sedation (6-48 h) and joint activity

\begin{tabular}{|c|c|c|c|c|c|}
\hline Index & & $6 \mathrm{~h}$ & $12 \mathrm{~h}$ & $24 \mathrm{~h}$ & $48 \mathrm{~h}$ \\
\hline \multirow[t]{3}{*}{ Ramsay } & Group C & $1.9 \pm 0.5$ & $1.7 \pm 0.5$ & $1.6 \pm 0.57$ & $1.6 \pm 0.6$ \\
\hline & Group D1 & $2.3 \pm 0.6^{\mathrm{aa}}$ & $2.2 \pm 0.6^{\mathrm{aa}}$ & $2.1 \pm 0.5^{\mathrm{aa}}$ & $2.2 \pm 0.5^{\mathrm{aa}}$ \\
\hline & Group D2 & $2.4 \pm 0.6^{\mathrm{aa}}$ & $2.3 \pm 0.6^{\mathrm{aa}}$ & $2.2 \pm 0.6^{\mathrm{aa}}$ & $2.3 \pm 0.6^{\mathrm{aa}}$ \\
\hline \multirow[t]{3}{*}{ Joint flexion } & Group C & & & $83.3 \pm 6.5$ & $107.7 \pm 7.6$ \\
\hline & Group D1 & & & $91.9 \pm 6.9^{\mathrm{aa}}$ & $112.3 \pm 6.4^{\mathrm{a}}$ \\
\hline & Group D2 & & & $92.1 \pm 7.7^{\text {aa }}$ & $113.9 \pm 6.5^{\text {aa }}$ \\
\hline
\end{tabular}

${ }^{\mathrm{a}} p<0.05$, ${ }^{\mathrm{aa}} p<0.01$, vs. group C.

\begin{tabular}{lllll}
\hline Group & $\begin{array}{l}\text { Nausea/ } \\
\text { vomiting, } n\end{array}$ & $\begin{array}{l}\text { The first time } \\
\text { leaving the sickbed, } h\end{array}$ & $\begin{array}{l}\text { Duration of } \\
\text { hospitalization, days }\end{array}$ & $\begin{array}{l}\text { Overall } \\
\text { satisfaction }\end{array}$ \\
\hline C & $4(13.3 \%)$ & $20.4 \pm 7.1$ & $12.8 \pm 4.5$ & $6.8 \pm 1.1$ \\
D1 & $2(6.7 \%)$ & $17.2 \pm 5.9^{\text {a }}$ & $11.7 \pm 4.8$ & $7.4 \pm 0.9^{\text {aa }}$ \\
D2 & $1(1.3 \%)$ & $14.1 \pm 4.7^{\text {aa, b }}$ & $11.5 \pm 4.2$ & $7.9 \pm 0.8^{\text {aa }}$ \\
\hline
\end{tabular}

${ }^{\mathrm{a}} p<0.05$, ${ }^{\mathrm{aa}} p<0.01$, vs. group C; ${ }^{\mathrm{b}} p<0.05$, vs. group D.

Table 4. Postoperative situation

Ropivacaine $(0.2 \%)$, which is commonly used in post-

increased at $24 \mathrm{~h}(p=0.001)$ and $48 \mathrm{~h}(p=0.034$ and 0.003 , respectively) postoperatively compared to the control group (Table 3 ).

The difference in incidence of postoperative nausea and vomiting and duration of hospitalization were not statistically significant among these three groups. The time for leaving the sickbed for the first time was significantly less in group D2 than that in the control group C ( $p=0.044$ and 0.001 , respectively), while the time for leaving the sickbed for the first time was less in group D2 than that in group D1 $(p=0.049)$. Overall satisfaction scores were higher in both $\mathrm{D} 1$ and $\mathrm{D} 2$ than in group $\mathrm{C}(p=0.002$ and 0.001 , respectively) (Table 4 ).

\section{Discussion}

This study revealed that low concentrations of ropivacaine combined with DEX exerted better analgesic and sedative effects than the lower dose of DEX. The higher dose of DEX significantly shortened the time leaving the sickbed for the first time and significantly reduced PVAS scores compared to the lower dose of DEX. Thus, our study suggests that high-dose DEX $\left(0.05 \mu \mathrm{g} \times \mathrm{kg}^{-1} \times \mathrm{h}^{-1}\right)$ combined with $0.15 \%$ ropivacaine exerts better postoperative analgesia and brings about functional recovery of the knee in elderly patients undergoing knee arthroplasty. operative continuous nerve block analgesia, has been shown to provide a reliable analgesic effect [12]. However, $0.2 \%$ ropivacaine may affect a patient's quadriceps strength, postpone their motion, and increase the risk of falling down during early exercise [13]. Furthermore, low concentrations of ropivacaine $(0.1 \%)$ may in turn induce inadequate analgesia [14]. Therefore, $0.15 \%$ ropivacaine combined with different concentrations of DEX were used in the present study.

DEX is a highly selective $\alpha_{2}$-adrenergic receptor agonist with sedative, analgesic, and opioid reduction benefits. Studies have shown that the intravenous infusion of DEX can reduce surgical stress with minimal impact on the blood circulation [17] and provides rational sedation, and it is widely used in intensive care units $[18,19]$. In the present study, it was found that when combined with DEX, performing the nerve block could provide more rational sedation effects 6-48 h after surgery and prevent the patient from being anxious, agitated, or restless. However, the maximum sedation score in all the groups was not more than 3 points. We assessed the sedation score in elderly patients in the absence of any external stimulus; this level of sedation did not affect the patient's joint functional exercise. We speculated that the sedation score under this condition was very low; therefore, we suggest that DEX combined with a low concentration of ropivacaine was safe for hospitalized patients. Moreover, DEX combined with a low ropivacaine 
concentration reduced the time for leaving the sickbed for the first time; this result verified our speculation. However, it remains to be determined whether continuous infusion of small DEX doses would cause sedation to be too deep and trigger respiratory depression in elderly patients.

DEX also increased the blockade effect of local anesthetics. Although there was no significant difference in resting pain between the ropivacaine group and DEX plus ropivacaine groups, after $6-48 \mathrm{~h}$ of active functional exercise, the combination of DEX provided a better postoperative analgesic effect. In addition, after 24 and $48 \mathrm{~h}$ of postoperative passive functional exercise, the knee flexion was increased in patients treated with DEX-ropivacaine combination, and postoperative pain was significantly reduced. These results are of great significance for patients undergoing early postoperative functional exercise. Besides, the study revealed that AVAS and joint activity were not significantly different between both DEX groups. Moreover, PVAS scores in the $0.05 \mu \mathrm{g} \times \mathrm{kg}^{-1} \times \mathrm{h}^{-1}$ DEX protocol were lower than in the $0.02 \mu \mathrm{g} \times \mathrm{kg}^{-1} \times \mathrm{h}^{-1}$ DEX protocol. However, these results suggest that the former may induce more pain relief and increase the flexion of the joint, revealing that a higher DEX dose has better clinical effects. Furthermore, the combination of DEX significantly shortened the time until the patient leaves the sickbed for the first time, especially $0.05 \mu \mathrm{g} \times \mathrm{kg}^{-1} \times \mathrm{h}^{-1}$ DEX significantly reduced the time compared to $0.02 \mu \mathrm{g} \times \mathrm{kg}^{-1} \times \mathrm{h}^{-1} \mathrm{DEX}$, which was correlated to ropivacaine with sensation and motor block separation [20], while DEX increased its block effect. After knee replacement, functional exercise is crucial for surgical outcomes, whereas early ambulation and functional exercise are beneficial for the recovery of joint function, the prevention of uncomplicated complications [21,22], and the reduction in the length of hospital stay [23]. This suggests that DEX combined with the low concentrations of ropivacaine may be of benefit in postoperative analgesia and for knee function exercises.

Although continuous femoral nerve block analgesia therapy with low-dose ropivacaine was not associated with DEX in terms of the incidence of adverse reactions (nausea and vomiting) and length of hospitalization, the combination regimen was significantly more effective than ropivacaine alone. Both ropivacaine and high- (0.05 $\left.\mu \mathrm{g} \times \mathrm{kg}^{-1} \times \mathrm{h}^{-1}\right)$ and low-dose DEX $\left(0.02 \mu \mathrm{g} \times \mathrm{kg}^{-1} \times \mathrm{h}^{-1}\right)$ improved patient satisfaction with postoperative analgesia. However, the satisfaction score is not statistically different between the two DEX protocols. Therefore, the $0.05 \mu \mathrm{g} \times \mathrm{kg}^{-1} \times \mathrm{h}^{-1} \mathrm{DEX}+0.15 \%$ ropivacaine regimen is advantageous for postoperative analgesia. Hence, we recommend the clinical use of this protocol.
Ultrasound-guided nerve block is noninvasive and can be accurately positioned, making the catheter more accessible to the nerves and improving drug effects and blockade [24]. Ultrasound-guided DEX plus topical ropivacaine for transverse fascia block, as a model for postoperative pain in the lower abdomen, revealed the advantage of ultrasound guidance and achieved better postoperative analgesic effects [25]. Thus, the application of ultrasound technology was instrumental in improving the analgesic effects of low ropivacaine concentrations combined with DEX.

The mechanism by which DEX produces analgesia is likely to be multifactorial. DEX has been suggested to produce analgesia by reducing the release of norepinephrine and causing $\alpha_{2}$-receptor-independent inhibitory effects on nerve fiber action potentials [26]. However, Brummett et al. [27] suggest that DEX causes analgesia by the inhibition of substance $\mathrm{P}$ released in the nociceptive pathway at the level of dorsal root neuron and by the activation of $\alpha_{2}$-adrenoceptors in the locus coeruleus of the brain. This analgesic effect of perineural DEX is caused by enhancement of a hyperpolarization-activated cation channel, which prevents the returning of the membrane potential of the nerve from a hyperpolarized state to a resting state for subsequent firing [27]. Thus, local anesthetics combined with DEX enhances inhibition to neural conduction, which produces better analgesia than monotherapy with local anesthetics. A limitation of this study is that the high- and low-dose DEX groups differed in many ways, although there was no statistical difference.

\section{Conclusion}

This study reveals that combination treatment with $0.05 \mu \mathrm{g} \times \mathrm{kg}^{-1} \times \mathrm{h}^{-1} \mathrm{DEX}$ and $0.15 \%$ ropivacaine continuous femoral nerve block can provide better postoperative analgesia than treatment without DEX, thus promoting postoperative exercise and early ground movements. The present study shows that $0.05 \mu \mathrm{g} \times \mathrm{kg}^{-1} \times \mathrm{h}^{-1} \mathrm{DEX}$ combined with $0.15 \%$ ropivacaine-continuous femoral nerve block guided by ultrasound is useful for elderly patients after knee arthroplasty, and improves postoperative analgesia and rehabilitation effects.

\section{Acknowledgments}

We are particularly grateful to all the people who have helped us with this paper and support from the Shanxi Provincial Youth Foundation Project (201601D021163). 


\section{Statement of Ethics}

This clinical trial was approved by the Ethics Committee of the Hospital, and a signed consent was obtained from the patients themselves or their family members.

\section{Disclosure Statement}

The authors declare that they have no competing interests.

\section{References}

1 Kopp SL, Børglum J, Buvanendran A, Horlocker TT, Ilfeld BM, Memtsoudis SG, et al. Anesthesia and analgesia practice pathway options for total knee arthroplasty: an evidence-based review by the American and European Societies of Regional Anesthesia and Pain Medicine. Reg Anesth Pain Med. 2017 Nov/Dec;42(6):683-97.

2 Lee YS. Comprehensive analysis of pain management after total knee arthroplasty. Knee Surg Relat Res. 2017 Jun;29(2):80-6.

3 Lavand'homme P, Thienpont E: Pain after total knee arthroplasty: a narrative review focusing on the stratification of patients at risk for persistent pain. Bone Joint J. 2015 Oct;97B(10 Suppl A):45-8.

4 Gaffney CJ, Pelt CE, Gililland JM, Peters CL. Perioperative pain management in hip and knee arthroplasty. Orthop Clin North Am. 2017 Oct;48(4):407-19.

5 Turnbull ZA, Sastow D, Giambrone GP, Tedore T. Anesthesia for the patient undergoing total knee replacement: current status and future prospects. Local Reg Anesth. 2017 Mar; 10:1-7.

6 Russo MW, Parks NL, Hamilton WG. Perioperative pain management and anesthesia: a critical component to rapid recovery total joint arthroplasty. Orthop Clin North Am. 2017 Oct;48(4):401-5.

7 Moucha CS, Weiser MC, Levin EJ. Current strategies in anesthesia and analgesia for total knee arthroplasty. J Am Acad Orthop Surg. 2016 Feb;24(2):60-73.

8 Cui Z, Liu X, Teng Y, Jiang J, Wang J, Xia Y. The efficacy of steroid injection in total knee or hip arthroplasty. Knee Surg Sports Traumatol Arthrosc. 2015 Aug;23(8):2306-14.

9 Luan H, Zhu P, Zhang X, Tian L, Feng J, Wu $Y$, et al. Effect of dexmedetomidine as an adjuvant to ropivacaine for wound infiltration in patients undergoing open gastrectomy: A prospective randomized controlled trial. Medicine (Baltimore). 2017 Sep;96(38):e7950.

10 Andersen JH, Grevstad U, Siegel H, Dahl JB, Mathiesen O, Jæger P. Does Dexmedetomidine have a perineural mechanism of action when used as an adjuvant to ropivacaine?: a paired, blinded, randomized trial in healthy volunteers. Anesthesiology. 2017 Jan;126(1): 66-73.
11 Li J, Wang H, Dong B, Ma J, Wu X. Adding dexmedetomidine to ropivacaine for femoral nerve block inhibits local inflammatory response. Minerva Anestesiol. 2017 Jun;83(6): 590-7.

12 Heo BH, Lee HJ, Lee HG, Kim MY, Park KS, Choi JI, et al. Femoral nerve block for patient undergoing total knee arthroplasty: Prospective, randomized, double-blinded study evaluating analgesic effect of perineural fentanyl additive to local anesthetics. Medicine (Baltimore). 2016 Sep;95(36):e4771.

13 Thambiah MD, Nathan S, Seow BZ, Liang S, Lingaraj K. Patient satisfaction after total knee arthroplasty: an Asian perspective. Singapore Med J. 2015 May;56(5):259-63.

14 Paauwe JJ, Thomassen BJ, Weterings J, van Rossum E, Ausems ME. Femoral nerve block using ropivacaine $0.025 \%, 0.05 \%$ and $0.1 \%$ : effects on the rehabilitation programme following total knee arthroplasty: a pilot study. Anaesthesia. 2008 Sep;63(9):948-53.

15 Lilot M, Meuret P, Bouvet L, Caruso L, Dabouz R, Deléat-Besson R, et al. Hypobaric spinal anesthesia with ropivacaine plus sufentanil for traumatic femoral neck surgery in the elderly: a dose-response study. Anesth Analg. 2013 Jul;117(1):259-64.

16 Kara I, Apiliogullari S, Oc B, Celik JB, Duman A, Celik C, et al. The effects of intrathecal morphine on patient-controlled analgesia, morphine consumption, postoperative pain and satisfaction scores in patients undergoing gynaecological oncological surgery. J Int Med Res. 2012;40(2):666-72.

17 Li Y, Wang B, Zhang LL, He SF, Hu XW, Wong GT, et al. Dexmedetomidine combined with general anesthesia provides similar intraoperative stress response reduction when compared with a combined general and epidural anesthetic technique. Anesth Analg. 2016 Apr;122(4):1202-10.

18 Xu B, Li Z, Zhou D, Li L, Li P, Huang H. The influence of age on sensitivity to dexmedetomidine sedation during spinal anesthesia in lower limb orthopedic surgery. Anesth Analg. 2017 Dec;125(6):1907-10.
19 Keating GM. Dexmedetomidine: A review of its use for sedation in the intensive care setting. Drugs. 2015 Jul;75(10):1119-30.

20 Gaudreault F, Drolet P, Fallaha M, Varin F. Modeling the anesthetic effect of ropivacaine after a femoral nerve block in orthopedic patients: a population pharmacokinetic-pharmacodynamic analysis. Anesthesiology. 2015 May;122(5):1010-20.

21 Hsu WH, Hsu WB, Shen WJ, Lin ZR, Chang $\mathrm{SH}, \mathrm{Hsu}$ RW. Circuit training enhances function in patients undergoing total knee arthroplasty: a retrospective cohort study. J Orthop Surg Res. 2017 Oct;12(1):156.

22 Harmelink KE, Zeegers AV, Tönis TM, Hullegie W, Nijhuis-van der Sanden MW, Staal JB. The effectiveness of the use of a digital activity coaching system in addition to a twoweek home-based exercise program in patients after total knee arthroplasty: study protocol for a randomized controlled trial. BMC Musculoskelet Disord. 2017 Jul;18(1):290.

23 Abbas C, Daher J. Pilot study: post-operative rehabilitation pathway changes and implementation of functional closed kinetic chain exercise in total hip and total knee replacement patient. J Bodyw Mov Ther. 2017 Oct; 21(4):823-9.

24 Elsharkawy H, Maheshwari A, Farag E, Mariano ER, Rosenquist RW. Development of technologies for placement of perineural catheters. J Anesth. 2016 Feb;30(1):138-47.

25 Mishra M, Mishra SP, Singh SP. Ultrasoundguided transversus abdominis plane block: what are the benefits of adding dexmedetomidine to ropivacaine? Saudi J Anaesth. 2017 Jan-Mar;11(1):58-61.

26 Gabriel JS, Gordin V. Alpha 2 agonists in regional anesthesia and analgesia. Curr Opin Anaesthesiol. 2001 Dec;14(6):751-3.

27 Brummett CM, Padda AK, Amodeo FS, Welch KB, Lydic R. Perineural dexmedetomidine added to ropivacaine causes a dosedependent increase in the duration of thermal antinociception in sciatic nerve block in rat. Anesthesiology. 2009 Nov;111(5): 1111-9. 